University of South Carolina

Scholar Commons

$10-21-2002$

\title{
GaN Homoepitaxy on Freestanding (1100) Oriented GaN Substrates
}

C. Q. Chen

M. E. Gaevski

W. H. Sun

E. Kuokstis

J. P. Zhang

See next page for additional authors

Follow this and additional works at: https://scholarcommons.sc.edu/elct_facpub

Part of the Electromagnetics and Photonics Commons, and the Other Electrical and Computer Engineering Commons

\section{Publication Info}

Published in Applied Physics Letters, Volume 81, Issue 17, 2002, pages 3194-3196.

(C)Applied Physics Letters 2002, American Institute of Physics (AIP).

Chen, C. Q., Gaevski, M. E., Sun, W. H., Kuokstis, E., Zhang, J. P., Fareed, R. S. Q., Wang, H. M., Yang, J. W., Simin, G., Khan, M. A., Maruska, H-P., Hill, D. W., Chou, M. M. C., \& Chai, B. (21 October 2002). GaN Homoepitaxy on Freestanding (1100) Oriented GaN Substrates. Applied Physics Letters, 81 (17), 3194-3196. http://dx.doi.org/10.1063/1.1516230

This Article is brought to you by the Electrical Engineering, Department of at Scholar Commons. It has been accepted for inclusion in Faculty Publications by an authorized administrator of Scholar Commons. For more information, please contact digres@mailbox.sc.edu. 


\section{Author(s)}

C. Q. Chen, M. E. Gaevski, W. H. Sun, E. Kuokstis, J. P. Zhang, R. S. Q. Fareed, H. M. Wang, J. W. Yang, Grigory Simin, M. A. Khan, Herbert-Paul Maruska, David W. Hill, Mitch M. C. Chou, and Bruce Chai 


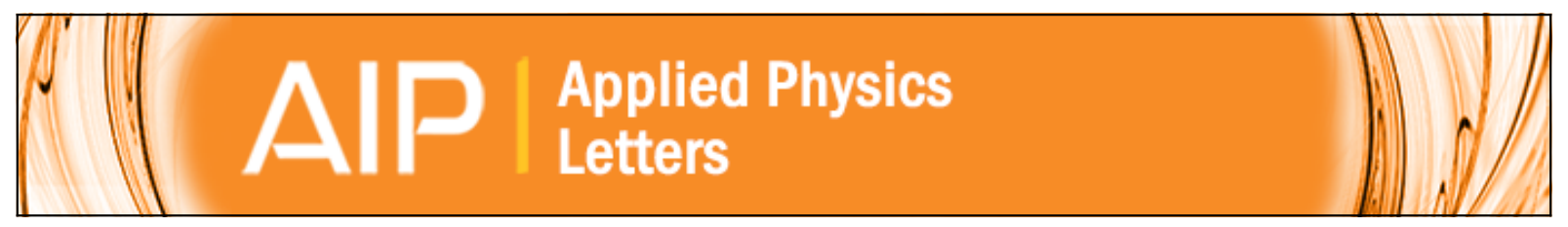

\section{GaN homoepitaxy on freestanding (1100) oriented GaN substrates}

C. Q. Chen, M. E. Gaevski, W. H. Sun, E. Kuokstis, J. P. Zhang, R. S. Q. Fareed, H. M. Wang, J. W. Yang, G. Simin, M. A. Khan, Herbert-Paul Maruska, David W. Hill, Mitch M. C. Chou, and Bruce Chai

Citation: Applied Physics Letters 81, 3194 (2002); doi: 10.1063/1.1516230

View online: http://dx.doi.org/10.1063/1.1516230

View Table of Contents: http://scitation.aip.org/content/aip/journal/apl/81/17?ver=pdfcov

Published by the AIP Publishing

\section{Articles you may be interested in}

Growth of single crystalline GaN thin films on $\mathrm{Si}(111)$ substrates by high vacuum metalorganic chemical vapor deposition using a single molecular precursor

J. Vac. Sci. Technol. B 22, 2144 (2004); 10.1116/1.1775193

Low-etch-pit-density GaN substrates by regrowth on free-standing GaN films

Appl. Phys. Lett. 80, 3718 (2002); 10.1063/1.1480108

Growth-temperature dependence of Er-doped GaN luminescent thin films

Appl. Phys. Lett. 80, 344 (2002); 10.1063/1.1434312

GaN homoepitaxy by metalorganic chemical-vapor deposition on free-standing GaN substrates Appl. Phys. Lett. 77, 1858 (2000); 10.1063/1.1311596

Effects of growth rate of a GaN buffer layer on the properties of $\mathrm{GaN}$ on a sapphire substrate J. Appl. Phys. 85, 8441 (1999); 10.1063/1.370625

\section{High-Voltage Amplifiers \\ - Voltage Range from $\pm 50 \mathrm{~V}$ to $\pm 60 \mathrm{kV}$ \\ - Current to 25A \\ Electrostatic Voltmeters \\ - Contacting \& Non-contacting \\ - Sensitive to $1 \mathrm{mV}$ \\ - Measure to $20 \mathrm{kV}$ \\ ENABLING RESEARCH AND \\ INNOVATION IN DIELECTRICS, \\ ELECTROSTATICS, MATERIALS, PLASMAS AND PIEZOS \\ TRek www.trekinc.com




\title{
GaN homoepitaxy on freestanding (1100) oriented GaN substrates
}

\author{
C. Q. Chen, M. E. Gaevski, W. H. Sun, E. Kuokstis, J. P. Zhang, R. S. Q. Fareed, \\ H. M. Wang, J. W. Yang, G. Simin, and M. A. Khan ${ }^{\text {a) }}$ \\ Department of Electrical Engineering, University of South Carolina, Columbia, South Carolina 29208
}

Herbert-Paul Maruska, David W. Hill, Mitch M. C. Chou, and Bruce Chai

Crystal Photonics, Inc., Sanford, Florida 32773

(Received 4 June 2002; accepted 30 August 2002)

\begin{abstract}
We report homoepitaxial GaN growth on freestanding (1100) oriented ( $M$-plane $\mathrm{GaN}$ ) substrates using low-pressure metalorganic chemical vapor deposition. Scanning electron microscopy, atomic-force microscopy, and photoluminescence were used to study the influence of growth conditions such as the V/III molar ratio and temperature on the surface morphology and optical properties of the epilayers. Optimized growth conditions led to high quality ( $1 \overline{1} 00)$ oriented GaN epilayers with a smooth surface morphology and strong band-edge emission. These layers also exhibited strong room temperature stimulated emission under high intensity pulsed optical pumping. Since for III-N materials the $(1 \overline{1} 00)$ crystal orientation is free from piezoelectric or spontaneous polarization electric fields, our work forms the basis for developing high performance III-N optoelectronic devices. (C) 2002 American Institute of Physics. [DOI: 10.1063/1.1516230]
\end{abstract}

Recently excellent progress has been made in the development of high-quality III-N devices. ${ }^{1-3}$ Nearly all the reported light emitting diodes, laser diodes, and high temperature and high power transistors employed III-N heterojunctions, which were deposited on either basal plane (0001) sapphire, $6 \mathrm{H}-$ or $4 \mathrm{H}-\mathrm{SiC}$, or free-standing $\mathrm{GaN}$ substrates. ${ }^{1-3}$ All of these deposited III-N films and heterostructures feature the polar (0001) orientation, and hence they exhibit strong piezoelectric and spontaneous polarization fields. ${ }^{4}$ These polarization fields give rise to a significant band bending, and thus reduce the overlap of the electronhole wave functions. ${ }^{5-7}$ This situation significantly reduces the optical emission from quantum wells. To avoid these polarization effects, in the past, $R$-plane sapphire substrates have been used for III-N optical devices. ${ }^{8}$ Heteroepitaxy on sapphire, however, results in a large number $\left(>10^{8} \mathrm{~cm}^{2}\right)^{9}$ of threading dislocations, which also serve to reduce the optical emission intensity. Homoepitaxy of $\mathrm{GaN}$ and $\mathrm{AlGaN}$ on nonpolar $M$-plane (1 100$)$ oriented bulk GaN substrates should in principle eliminate these problems. ${ }^{10,11}$ This serves as the motivation for our work reported here.

GaN bulk crystals with (1100) surface ( $M$-plane) were grown by hydride vapor phase epitaxy (HVPE) ${ }^{12}$ on the closely lattice matched (100) plane of $\mathrm{LiAlO}_{2} \cdot{ }^{13}$ Boules of $\mathrm{LiAlO}_{2}$ about $20 \mathrm{~cm}$ long were pulled from the melt by the Czochralski method, and 50-mm-diameter $\mathrm{LiAlO}_{2}$ wafers were subsequently sawed from these boules and given a mirror-smooth surface by polishing; details will be presented elsewhere. ${ }^{14}$ After depositing about $350 \mu \mathrm{m}$ of $\mathrm{GaN}$, the $\mathrm{LiAlO}_{2}$ substrate was removed with wet acid etching. Thus, freestanding ( $1 \overline{1} 00)$ oriented $\mathrm{GaN}$ templates were obtained, that served as the starting substrates for our study. The phase purity of the GaN templates was examined by X-ray diffraction (XRD). The $2 \theta-\omega$ XRD scans exhibit only two sharp GaN (1 $\overline{1} 00)$ and $(2 \overline{2} 00)$ peaks [see Fig. 1(a)]. By Hall mea-

a)Electronic mail: asif@engr.sc.edu surements, their room temperature free-electron concentration and mobility were determined to be $1 \times 10^{19} \mathrm{~cm}^{-3}$ and $92 \mathrm{~cm}^{2} / \mathrm{Vs}$, respectively.

The homoepitaxial growth on the GaN templates was carried out by low-pressure metalorganic chemical vapor deposition (MOCVD). Triethylgallium and $\mathrm{NH}_{3}$ were used as the precursors for $\mathrm{Ga}$ and $\mathrm{N}$, respectively. The reactor pressure and temperature were kept at 76 Torr and $1000^{\circ} \mathrm{C}$, and $\mathrm{H}_{2}$ was used as carrier gas during the growth. Several $\mathrm{GaN}$ epilayers with thicknesses ranging from 2 to $4 \mu \mathrm{m}$ were grown. The surface morphologies of these layers were then studied using a Nomarsky optical microscope, scanning electron microscopy (SEM), and an atomic force microscope (AFM). Their room and low-temperature $(10 \mathrm{~K})$ photholuminescence (PL) spectra were measured using a cw He-Cd laser (operating at $325 \mathrm{~nm}$ ) as a low-intensity excitation source and a pulsed $(\tau=0.4 \mathrm{~ns})$ nitrogen laser (at $337 \mathrm{~nm}$ ) for a high-excitation intensity source.

The crystal orientation of GaN homoepitaxial layer was studied by electron backscattered diffraction technique (EBSD). It provides the information on the orientation of the top epilayer with a high spatial resolution. ${ }^{15}$ Using an accelerating voltage of $20 \mathrm{kV}$ and a sample tilt of $70^{\circ}$, assures the EBSD signal will originate from the top $1 \mu \mathrm{m}$ of the examined sample. Since the thickness of the deposited homoepitaxial $\mathrm{GaN}$ epilayer was $4 \mu \mathrm{m}$, there is no contribution to the EBSD signal from the GaN substrate template. Therefore, a careful indexing of all Kikuchi lines using the commercial Opal Inc. ${ }^{\mathrm{TM}}$ software allows a precise identification of our sample surface orientation. Figure 1(b) shows a typical diffraction pattern obtained from the epilayer, where the numbers indicate crystallographic directions. Taking into account the sample tilt angle $70^{\circ}$, one can find that normal direction to the sample surface will exactly coincide with [1 100$]$. Thus, surface orientation was determined to be (1100). From the EBSD measurements on different spots on the 

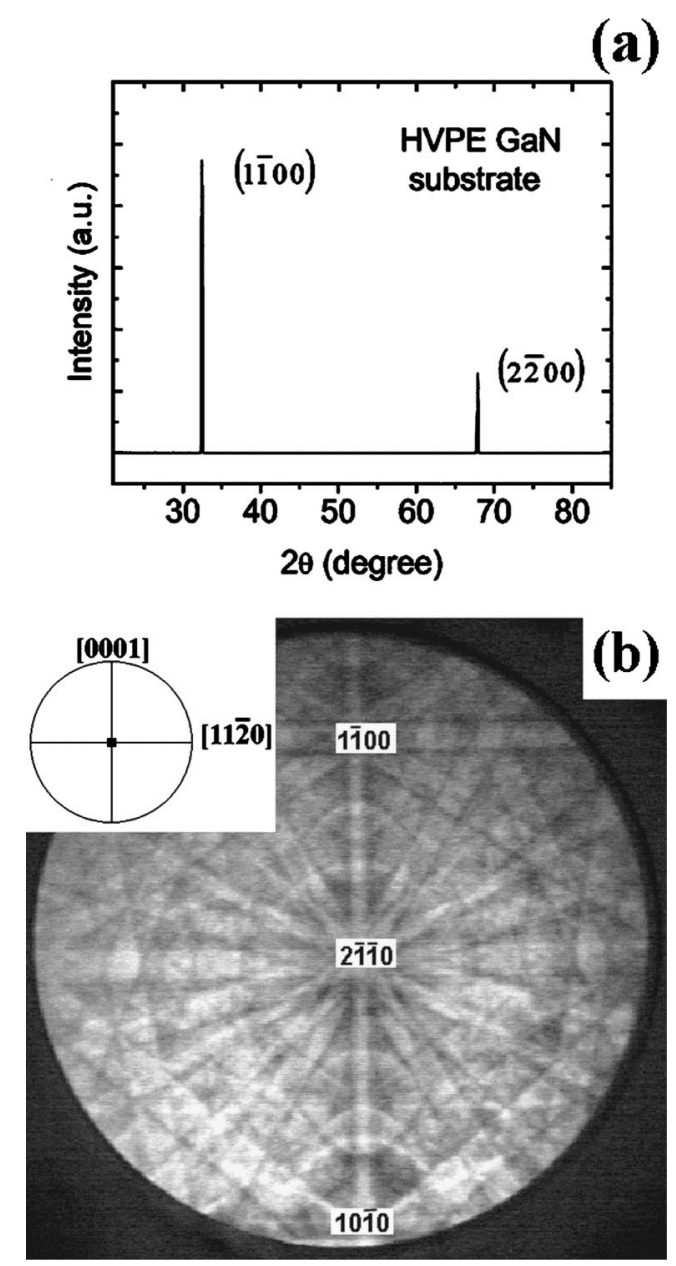

FIG. 1. (a) The $2 \theta-\omega$ XRD scan data from HVPE (1 100$)$ oriented GaN template. (b) Electron backscattered diffraction pattern obtained from epilayers grown on $M$-plane of free-standing $\mathrm{GaN}$ substrates. Insert shows the $\{1 \overline{1} 00\}$ pole-figure. Black square on the pole-figure indicates the layer surface orientation, which is exactly $(1 \overline{1} 00)$.

sample surface, we observed a high degree of uniformity of the layer orientation.

At a growth temperature of $1000^{\circ} \mathrm{C}$, we found the surface morphology of our layers to be affected by the V/III molar ratio. In Fig. 2 we show the surface AFM scans for $4-\mu \mathrm{m}$-thick homoepitaxial $\mathrm{GaN}$ epilayers grown using V/III ratios of 2500 and 5000. At the lower V/III ratio [see Fig. 2(a)], the layers exhibited a relatively smoother surface with a rms roughness of around $0.7 \mathrm{~nm}$ for a $2 \mu \mathrm{m} \times 2 \mu \mathrm{m}$ scan area. At the higher V/III molar ratio, the rms roughness increases to about $2.0 \mathrm{~nm}$ for the same scan area [Fig. 2(b)]. The increased roughness at the higher $\mathrm{NH}_{3}$ flow, we believe, may result from the shorter diffusion length of the adatoms before reaction. These surfaces roughness values, though slightly higher than $C$-plane $\mathrm{GaN}$ epilayers, are still very reasonable for device fabrication needs. The SEM studies also confirm the morphology observations made using the AFM analysis.

AFM scans of Fig. 2 also reveal stripe-like growth features aligned along the $[11 \overline{2} 0]$ direction. These stripe features may also result from the different migration lengths of adatoms along [0001] and [1120] directions. Additional evidence of the different migration lengths is provided by the observation that these stripe-like growth features become

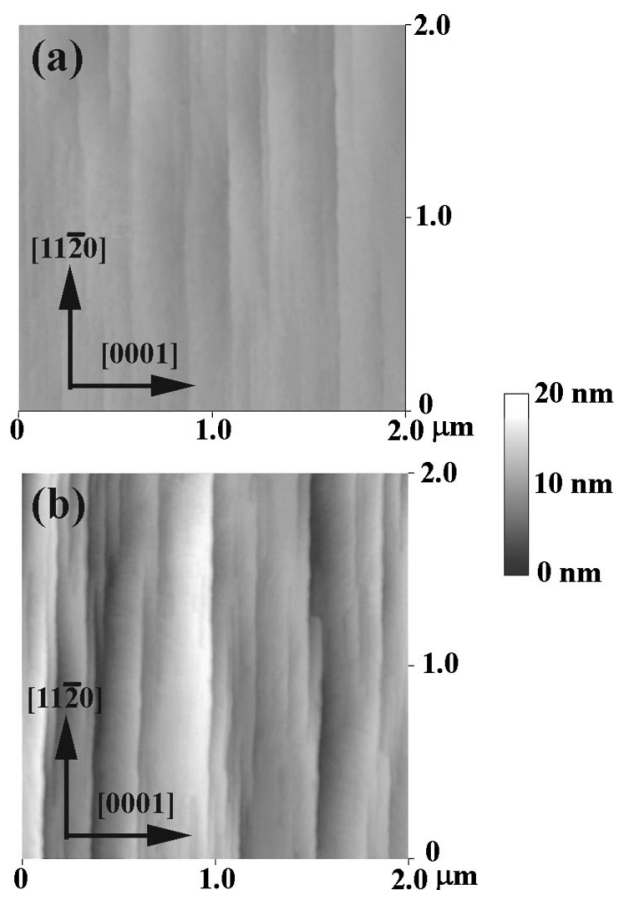

FIG. 2. AFM images of (1 $1 \overline{1} 00)$ oriented GaN homoepitaxial layers. The stripes in images run along [11 $\overline{2} 0]$ direction. The films were grown at V/III molar ratios of (a) 2500 and (b) 5000 .

more pronounced at higher growth temperatures. This is to be expected if surface migration is the key contributor controlling the growth process. A detailed study of these surface morphology features to analyze the growth mechanism is currently underway and will be reported separately.

The influence of growth temperature and V/III molar ratio on the luminescent properties of the homoepitaxial GaN films was also studied. These data for the two films of Fig. 2 are included in Fig. 3. As seen, in addition to the band-edge emission peak at $3.43 \mathrm{eV}$, a strong yellow band around 2.1 $\mathrm{eV}$ is also observed. This yellow emission band decreases with an increase of the V/III molar ratio. However the bandedge emission also decreases slightly with the higher V/III ratio. Increasing growth temperature up to $1050^{\circ} \mathrm{C}$ could also reduce the yellow emission band. This PL band may arise from a transition between a shallow donor and a deep acceptor level. ${ }^{16,17}$ More experiments are underway to determine its origin. In the inset to Fig. 3, we include the near band-edge luminescence at $(10 \mathrm{~K})$ from the $M$-plane $\mathrm{GaN}$ film grown with a V/III ratio of 5000. As seen, the low tem-

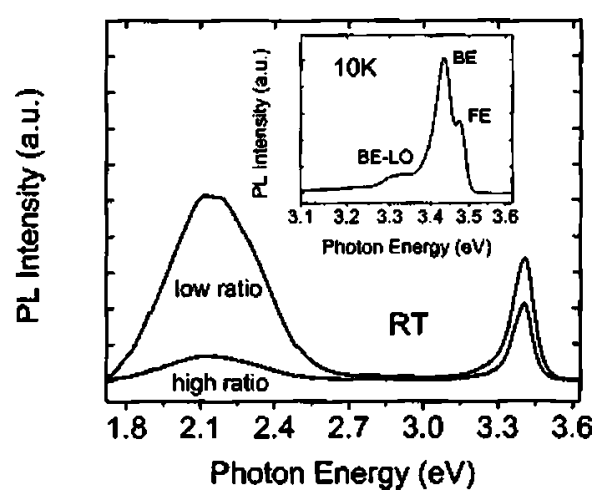

FIG. 3. PI spectra of $M$-plane GaN epilayers under different V/III molar ratios. The inset shows the near band-edge emission at $10 \mathrm{~K}$. 


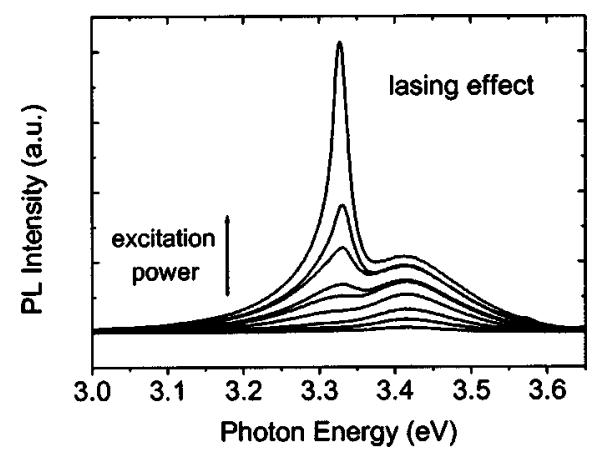

FIG. 4. Room temperature stimulated emission spectra of GaN epilayer under different level of excitation power intensity by using a nitrogen laser.

perature PL spectra exhibit an emission structure arising from the free and bound excitons. This behavior is similar to what is typically observed for the high quality GaN films grown over $C$-plane oriented substrates. ${ }^{18,19}$ For the PL signals of Fig. 3, we did not observe any significant polarization dependence of the emission spectra with the electric-field vector oriented either $E \| C$ or $E \perp C$. This was found in spite of the $c$-axis lying in the film surface plane. This can happen if the allowed optical transitions for both polarizations are to the $B$ valence subband, which is located very close $(\sim 6 \mathrm{meV})$ to the $A$ subband.

To further establish the high optical quality of the homoepitaxial $(1 \overline{1} 00)$ oriented GaN epilayers, pulsed nitrogen laser excited PL was measured at room temperature. Figure 4 shows these PL spectra under different excitation levels. As seen at the low excitation levels, the PL is dominated by a broad band, presumably arising from an electron-hole plasma emission. At high pump excitations (threshold approximately $1 \mathrm{MW} / \mathrm{cm}^{2}$ ) a strong and narrow stimulated emission line at $3.34 \mathrm{eV}$ appears on the long-wave side of the $\mathrm{GaN}$ spectrum. This behavior is very similar to that observed for high quality $c$-plane deposited GaN films. ${ }^{20,21}$

In summary, we report low-pressure MOCVD growth of (11 100 ) oriented GaN epilayers of high crystal phase purity and high optical quality on freestanding HVPE grown GaN substrates. Data is presented showing the effect of growth conditions such as V/III molar ratio and temperature on their surface morphology and optical properties. Room temperature stimulated emission under pulsed optical pumping confirms the high optical quality. In general the structural and optical quality of the homoepitaxial $M$-plane GaN layers is comparable to that of the high-quality $C$-plane oriented films on basal plane sapphire, $4 \mathrm{H}$ - or $6 \mathrm{H}-\mathrm{SiC}$ substrates. Our work therefore forms the basis for studying the role that spontaneous and piezoelectric polarizations play in influencing the characteristics of III-N optoelectronic devices.

The authors gratefully acknowledge the technical help from Q. H. Zhang and J. Gallagher. This work at USC was partially supported by the Ballistic Missile Defense Organization (BMDO) under Army SMDC Contract No. DASG6098-1-0004, monitored by T. Bauer, Dr. B. Strickland, and Dr. K. Wu.

${ }^{1}$ S. J. Pearton, J. C. Zolper, R. J. Shul, and F. Ren, J. Appl. Phys. 86, 1 (1999).

${ }^{2}$ M. A. Khan, J. W. Yang, W. Knap, E. Frayssinet, X. Hu, G. Simin, P. Prystawko, M. Leszczynski, I. Grzegory, S. Porowski, R. Gaska, M. S. Shur, B. Beaumont, M. Teisseire, and G. Neu, Appl. Phys. Lett. 76, 3807 (2000).

${ }^{3}$ O. Ambacher, J. Phys. D 31, 2653 (1998).

${ }^{4}$ F. Bernardini, V. Fiorentini, and D. Vanderbilt, Phys. Rev. B 56, 10024 (1997).

${ }^{5}$ T. Deguchi, K. Sekiguchi, A. Nakamura, T. Sota, R. Matsuo, S. Chichibu, and S. Nakamura, Jpn. J. Appl. Phys., Part 2 38, L914 (1999).

${ }^{6}$ N. Grandjean, B. Damilano, S. Dalmasso, M. Leroux, M. Laügt, and J. Massies, J. Appl. Phys. 86, 3714 (1999).

${ }^{7}$ S. Ghosh, P. Waltereit, O. Brandt, H. T. Grahn, and K. H. Ploog, Phys. Rev. B 65, 075202 (2002).

${ }^{8}$ S. Tripathy, R. K. Soni, H. Asahi, K. Iwata, R. Kuroiwa, K. Asami, and S. Gonda, J. Appl. Phys. 85, 8386 (1999).

${ }^{9}$ S. D. Lester, F. A. Ponce, M. G. Crawford, and D. A. Steigerwald, Appl. Phys. Lett. 66, 1249 (1995).

${ }^{10}$ P. Waltereit, O. Brandt, A. Trampert, H. T. Grahn, J. Menniger, M. Ramsteiner, M. Reiche, and K. H. Ploog, Nature (London) 406, 865 (2000).

${ }^{11}$ P. Waltereit, O. Brandt, M. Ramsteiner, A. Trampert, H. T. Grahn, J. Menniger, M. Reiche, and K. H. Ploog, J. Cryst. Growth 227, 437 (2001).

${ }^{12}$ H. P. Maruska and J. J. Tietjen, Appl. Phys. Lett. 15, 327 (1969).

${ }^{13}$ K. Xu, J. Xu, P. Z. Deng, Y. Z. Zhou, G. Q. Zhou, R. S. Qiu, and Z. J. Fang, J. Cryst. Growth 193, 127 (1998).

${ }^{14}$ B. Chai and M. M. C. Chou (unpublished).

${ }^{15}$ C. Trager-Cowan, S. K. Manson-Smith, D. A. Cowan, F. Sweeney, D. McColl, A. Mohammed, R. Timm, P. G. Middleton, K. P. O. Donnell, D. Zubia, and S. D. Hersee, Mater. Sci. Eng., B 82, 19 (2001).

${ }^{16}$ O. Briot, J. P. Alexis, S. Sanchez, B. Gil, and R. L. Aulombard, Solid-State Electron. 41, 315 (1997).

${ }^{17}$ S. O. Kucheyev, M. Toth, M. R. Philips, J. S. Williams, C. Jagadish, and G. Li, J. Appl. Phys. 91, 5867 (2002).

${ }^{18}$ J. H. Edgar, S. Strite, I. Akasaki, H. Amano, and C. Wetzel, Gallium Nitride and Related Semiconductors (Short Run, Exeter, UK, 1999).

${ }^{19}$ E. Feltin, B. Beaumont, M. Laügt, P. De Mierry, P. Vennegues, M. Leroux, and P. Gibart, Phys. Status Solidi A 188, 531 (2001).

${ }^{20}$ G. P. Yablonskii, E. V. Lutsenko, V. N. Pavlovskii, I. P. Marko, B. Schineller, M. Heuken, and K. Heime, Mater. Sci. Eng., B 80, 322 (2001).

${ }^{21}$ H. Amano, T. Asahi, and I. Akasaki, Jpn. J. Appl. Phys., Part 1 29, 205 (1990). 